\title{
Complexity of the Anisotropy of Magnetic Susceptibility in Single-Phase Deformed, Low-Grade, Cleaved Mudstone
}

\author{
Timothy N. Debacker ${ }^{1,}$, , Philippe Robion ${ }^{2, b}$ and Manuel Sintubin ${ }^{1, c}$ \\ ${ }^{1}$ Structural Geology \& Tectonics Group, Katholieke Universiteit Leuven, Redingenstraat 16, B-3000 \\ Leuven, Belgium \\ ${ }^{2}$ Departement des Sciences de la Terre, Université de Cergy-Pontoise, 8 Avenue du Parc, Le \\ Campus, Bat. I, 95031 Cergy-Pontoise Cedex, France \\ atimothy.debacker@geo.kuleuven.ac.be, ${ }^{b}$ philippe.robion@geol.u-cergy.fr, \\ cmanuel.sintubin@geo.kuleuven.ac.be
}

Keywords: AMS, AARM, Brabant Massif, cleavage, Moesian Platform, strain

\begin{abstract}
The anisotropy of magnetic susceptibility (AMS) is often interpreted in terms of strain. However, since AMS is controlled by all magnetic (s.1.) carriers present, an AMS interpretation is not straightforward, especially in the presence of composite magnetic fabrics. Considering the large number of factors that may influence rock mineralogy (e.g. sediment source area, metamorphism), it becomes clear that one cannot interpret AMS in terms of strain without applying additional techniques that allow determining the nature and preferred orientation of all magnetic (s.l.) carriers likely influencing the measured AMS. This is discussed using samples from the Brabant Massif (Belgium) and the Moesian Platform (E-Romania).
\end{abstract}

\section{Introduction}

Because of the common scarcity of classical strain markers and the often fine-grained nature of the deposits, performing strain analyses in slate belts may be difficult. As an alternative one may apply more analytical methods such as phyllosilicate X-ray pole figure goniometry [1] and the analysis of the anisotropy of magnetic susceptibility (AMS) [2]. During the last 20 years, especially the latter, which, in contrast to the former, can be applied in a large variety of rock types, has commonly been considered as a qualitative and sometimes even a quantitative measure of tectonic strain $[2,3]$.

However, AMS is a result of all magnetic (s.1.) carriers present [2,3,4]. If effectively controlled by two differently oriented carrier populations, the relationship with strain becomes questionable [4]. Housen et al. [4] examined this effect of so-called composite magnetic fabrics on AMS by means of experiments and numerical studies, using synthetic samples with two differently oriented populations of magnetite and demonstrated that the orientation of the susceptibility ellipsoid, as well as the ellipsoid shape and the degree of anisotropy are strongly influenced by the orientation and relative concentration of the two orientation populations of magnetic carriers. Recently, similar trends were observed on the basis of natural samples [5]. In the present paper, we present new data that confirm earlier conclusions $[4,5]$ and further emphasise the complexity of AMS.

\section{Investigated Lithologies}

Samples were taken from the Lower Palaeozoic Brabant Massif (N-Belgium) and from the Moesian Platform in Central Dobrogea (E-Romania). Both low-grade metamorphic areas only show evidence of one regional deformation event, mainly reflected by folds and a cogenetic, poorly to well-developed cleavage. Only the most fine-grained, uniform lithologies were used (claystone to fine-grained siltstone). In the Brabant Massif, Cambrian (Jodoigne, Tubize, Oisquercq and Mousty formations), Upper Ordovician (Hospice-de-Rebecq and Madot formations) and middle and upper Silurian units were sampled (Vichenet and Ronquières formations) [6]. In the Moesian Platform Neoproterozoic turbidites were sampled, which occur over a large area and show marked differences in cleavage intensity between different outcrop areas. 


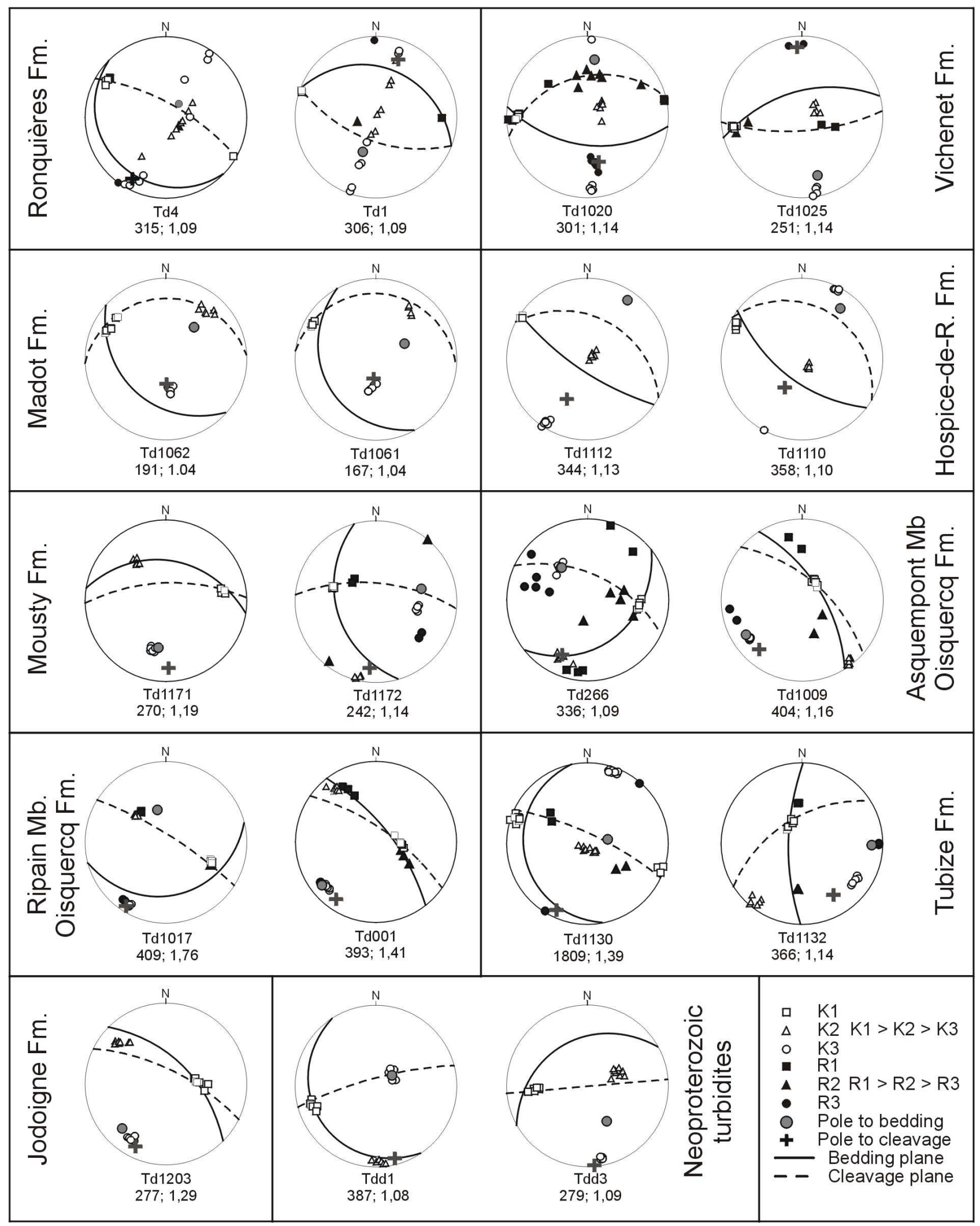

Fig. 1: Lower-hemisphere equal-area stereographic projections of selected samples of the investigated lithologies, showing the principal AMS $(\mathrm{Kx})$ and AARM-axes $(\mathrm{Rx})$, cleavage and bedding. Below each sample number, $\mathrm{Km}$ is given, followed by $\mathrm{Pj}$. 


\section{Methodology}

Magnetic Anisotropy Studies. Samples consist of oriented hand specimens that were cut into cubes, on average 7 per sample, with size $2 \times 2 \times 2 \mathrm{~cm}$. Both the anisotropy of the low field magnetic susceptibility (AMS) and of the anhysteretic remanent magnetization (AARM) were investigated. Whereas AMS represents the contribution of all magnetic constituents of a rock, AARM only reflects the ferromagnetic fraction [7].

AMS was measured with a KLY3S kappabridge [8]. The eigenvectors of the susceptibility tensor, K1, K2 and $\mathrm{K} 3(\mathrm{~K} 1>\mathrm{K} 2>\mathrm{K} 3)$ reflect the orientation and shape of the susceptibility ellipsoid. Three different eigenvector arrangements are used: the corrected degree of anisotropy $\mathrm{Pj}$, reflecting the degree of preferred orientation [9], the shape parameter $\mathrm{T}$, being a measure of the shape of the susceptibility ellipsoid, with prolate ellipsoids in case $-1<\mathrm{T}<0$ and oblate ellipsoids in case $0<\mathrm{T}<1$ [9], and the mean susceptibility $\mathrm{Km}$ [10]. In order to investigate the effect of mineralogy on $\mathrm{AMS}, \mathrm{Pj}$ and $\mathrm{Km}$ are compared. $\mathrm{On}$ a $\mathrm{Pj} / \mathrm{Km}$ plot the paramagnetic contribution has an upper limit around $\mathrm{Pj} \sim 1.2-1.3$ and $\mathrm{Km} \sim 300-50010^{-6}$ SI $[11,12]$.

AARM is based on the ability of samples to acquire a remanent magnetization when an alternating field is applied in the presence of a small direct field [7]. Magnetization is imparted along a chosen sample direction in an alternating field peak of $100 \mathrm{mT}$ with a coaxial direct field of $100 \mu \mathrm{T}$. Before processing magnetization, the sample is demagnetized with an alternating field of $100 \mathrm{mT}$. Magnetization and demagnetization is performed by the LAD-3 AF device (AGICO), and the sample is measured with a JR5 spinner magnetometer. The AARM tensor is determined by using the Jelinek procedure [13]. Because of the maximum value of the alternating field applied, the main minerals controlling AARM are magnetite and low-coercivity pyrrhotite.

Ferromagnetic Mineralogy. Ferromagnetic mineralogy was investigated on the basis of a coercivity/blocking temperature spectrum analysis by applying a stepwise demagnetization of a "three axis" isothermal remanent magnetization following the procedure of Lowrie [14]. We applied three successive saturation fields $(1.4 \mathrm{~T}, 0.6 \mathrm{~T}$ and $0.12 \mathrm{~T})$ along three perpendicular directions. These are then demagnetized thermally from 25 to $700^{\circ} \mathrm{C}$ in steps of $50^{\circ} \mathrm{C}$, with finer steps around $325^{\circ} \mathrm{C}$ and $580^{\circ} \mathrm{C}$, the Curie temperatures of pyrrhotite and magnetite respectively.

X-ray pole figure goniometry. Mica $(001)(\mathrm{d}=10 \AA)$ and chlorite $(002)(\mathrm{d}=7 \AA)$ orientation distributions were measured by means of an $\mathrm{X}$-ray pole figure goniometer. Pole figure measurements were performed using Fe-filtered Co-radiation (40kV x $30 \mathrm{~mA})$. Complete normalised pole figures were obtained by combining incomplete pole figure measurements, performed in transmission mode, on two mutually perpendicular sections of the sample, both perpendicular to the main foliation (bedding or cleavage) $[15,5]$.

\section{AMS and AARM Orientation Analysis}

Fig. 1 shows the orientation of the principal AMS and, where possible, AARM axes, relative to cleavage and bedding for selected samples of the investigated lithostratigraphic units. In all cases the maximum susceptibility axis (K1) coincides with the intersection lineation between cleavage and bedding. In contrast, the minimum susceptibility axis (K3) shows variable orientations with respect to cleavage and bedding. In some lithostratigraphic units $\mathrm{K} 3$ always coincides with the pole to cleavage (Madot Formation, high-susceptibility zones of Tubize Formation), in other units K3 always coincides with the bedding pole (Asquempont Member of Oisquercq Formation), but in most units $\mathrm{K} 3$ has a variable orientation in between the cleavage pole and the bedding pole. Also the relative orientation of the principal AARM axes is different for different lithostratigraphic units, with some units having a minimum remanence axis (R3) generally parallel to the cleavage pole (Ronquières and Vichenet formations, high-susceptibility zones of Tubize Formation), other units having R3 generally parallel to the bedding pole (Asquempont and Ripain members of Oisquercq 
Formation, low-susceptibility zones of Tubize Formation), and yet other units having R3 seemingly in between the bedding pole and the cleavage pole (Mousty Formation).

It is tempting to interpret those cases in which $\mathrm{K} 3$ coincides with the cleavage pole as a result of a stronger cleavage fabric and hence a higher tectonic strain. However, only samples TD1017 (Ripain Member) and TDD3 (Neoproterozoic turbidites) have a stronger cleavage fabric than the other samples of the same lithostratigraphic unit. In contrast, in the vast majority of the samples, the fact whether or not K3 coincides with the cleavage pole or the bedding pole depends entirely on the preferred orientation and concentration of the different groups of magnetic (s.1.) carriers [5].

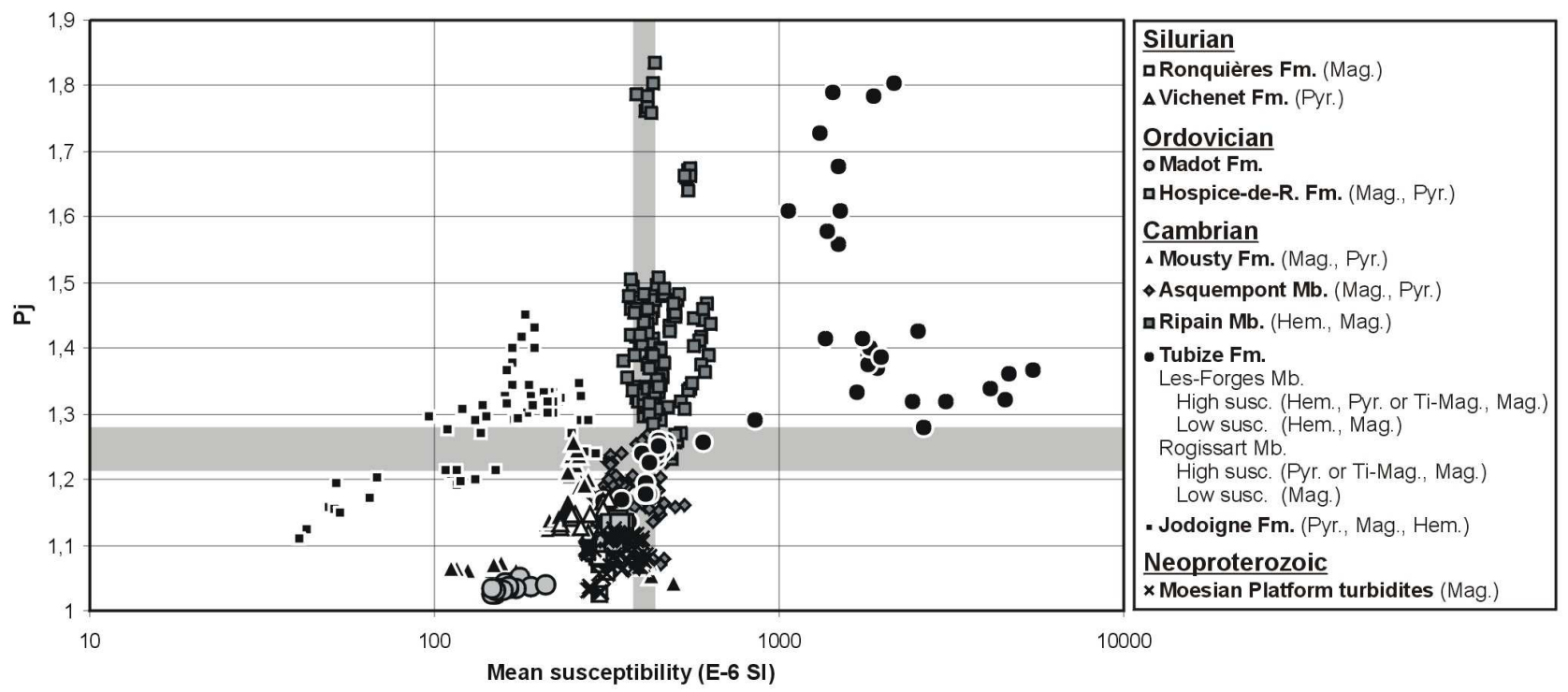

Fig. 2: Mean susceptibility $(\mathrm{Km})$ versus corrected degree of anisotropy $(\mathrm{Pj})$. For each stratigraphic unit the ferromagnetic mineralogy is listed in decreasing order of concentration (Mag.: magnetite; Pyr., pyrrhotite; Hem.: hematite).

\section{Magnetic Carrier Types}

Fig. 2 shows a graph of the mean susceptibility $\mathrm{Km}$ versus the corrected degree of anisotropy $\mathrm{Pj}$, on which the mean of the upper limit of the paramagnetic contribution is marked. For the majority of the samples both paramagnetic and ferromagnetic carriers are likely to contribute to AMS. Only in the case of the Ripain Member and the high-susceptibility samples of the Tubize Formation, predominantly situated above the upper limit of the paramagnetic contribution, can one expect AMS to be controlled almost entirely by the ferromagnetic carriers. Likewise, an AMS controlled almost entirely by paramagnetic carriers is expected only for those samples with a very low $\mathrm{Pj}$ and Km (e.g. Madot Formation and some samples of the Mousty Formation and the Jodoigne Formation).

Small amounts of ferromagnetic carriers are present in all investigated lithologies (Fig. 2). The ferromagnetic mineralogy remains fairly constant within individual lithostratigraphic units, but often shows marked differences between different lithostratigraphic units, both between different formations and between different members of the same formation (e.g. Ripain and Asquempont members of Oisquercq Formation) [5]. Considering this pronounced stratigraphic variation of ferromagnetic mineralogy it is not surprising that also AMS may show stratigraphic variations.

The main paramagnetic minerals present in the investigated rocks are chlorite and mica, which both, judging from X-ray pole figure goniometry on a variety of lithologies in the Brabant Massif, have a preferred alignment parallel to cleavage. One exception is the Asquempont Member, where chlorite is oriented parallel to bedding [5]. 


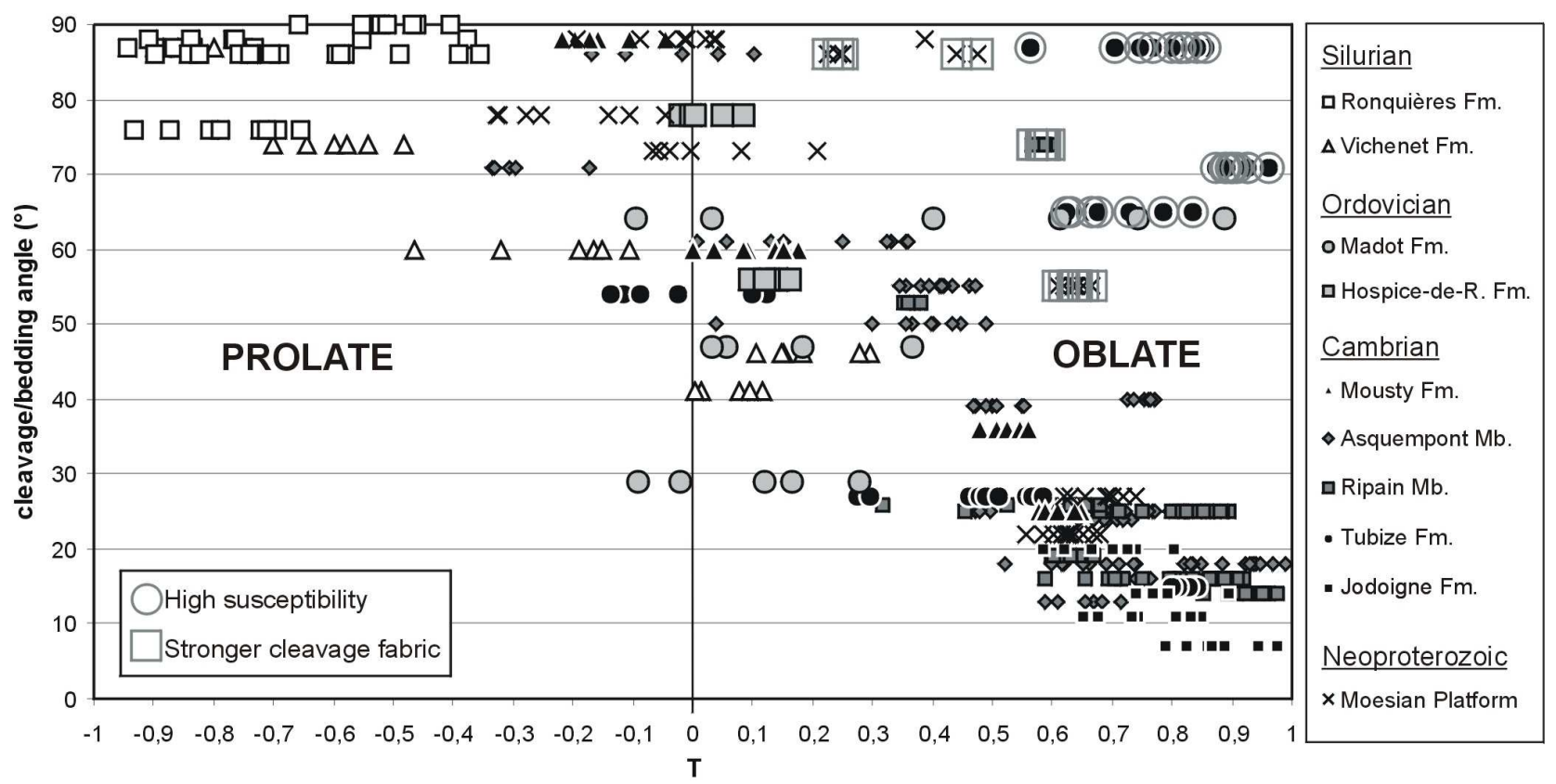

Fig. 3: Relationship between $\mathrm{T}$ and the cleavage/bedding angle.

\section{Composite Magnetic Fabrics}

A marked relationship exists between the shape parameter $\mathrm{T}$ and the angle between cleavage and bedding: more oblate susceptibility ellipsoids for small angles between cleavage and bedding and more prolate ellipsoids for large angles (Fig. 3) [5]. A similar relationship was observed between T and the angle between two synthetic magnetite orientation distributions [4]. This led Debacker et al. [5] to explain this relationship and also the mismatches between $\mathrm{K} 3$ and the pole to bedding and cleavage in terms of the combined effect of bedding- and cleavage-parallel paramagnetic and ferromagnetic carriers. If this interpretation holds, then the relationship between $\mathrm{T}$ and cleavage/bedding angle is expected to be absent when AMS is controlled only by one orientation population of magnetic (s.l.) carriers. As can be seen on Fig. 3, several samples do not show this relationship. These are the samples of the high-susceptibility zones of the Tubize Formation, the samples of the Madot Formation, one sample (TD1017) of the Ripain Formation and two samples (TDD3 and TDD9) of the Neoproterozoic turbidites. As pointed out higher, in the highsusceptibility zones of the Tubize Formation, AMS is likely to be controlled entirely by the ferromagnetic carriers (pyrrhotite or Ti-magnetite). Likewise, in the Madot Formation, having a very low $\mathrm{Km}$ and $\mathrm{Pj}$, the effect of ferromagnetic carriers is expected to be minimal and AMS is likely to be controlled only by the paramagnetic carriers. In the Neoproterozoic turbidites, the shift of samples TDD3 and TDD9 towards a higher $\mathrm{T}$ with respect to the other samples may be interpreted in terms of strain. These two samples do not have a significantly different $\mathrm{Pj}$ and $\mathrm{Km}$ with respect to the other samples of the same lithology but are the only ones with a much better developed cleavage and with K3 parallel to the cleavage pole. In the case of sample TD1017 of the Ripain Member, both a mineralogical and a strain interpretation seem possible.

\section{Discussion and Conclusions}

Although the analysed samples are quite simple in terms of mineralogy (consisting mainly of white mica, chlorite and quartz, with only traces of other minerals), their AMS is quite complex. Considering the influence of a large number of factors on the presence, concentration and orientation of magnetic (s.l.) minerals (e.g. sediment source area, sedimentation and compaction, diagenesis, alteration and metamorphism, tectonic deformation, pre-, syn- and post-tectonic fluid 
flow) it becomes clear that composite magnetic fabrics are probably quite common and that for a given rock type within a given area one should not attempt an interpretation of AMS without sufficient knowledge of the magnetic (s.l.) carriers present.

Composite magnetic fabrics of paramagnetic and ferromagnetic carriers should be expected in case $\mathrm{Km}$ and $\mathrm{Pj}$ approach the upper limit of the paramagnetic contribution [11,12]. The presence of composite magnetic fabrics is reflected by a $\mathrm{K} 1$ that is parallel to the fabric intersection lineation, a K3 that shows a variable orientation with respect to the fabric elements, and a clear relationship between $\mathrm{T}$ and the angle between the fabric elements [4,5]. Only when it is proven that within a given lithology in a given area AMS is entirely controlled by only one magnetic carrier population can one consider using it for qualitative and possibly even quantitative strain analyses. If not, one may attempt to further unravel AMS in terms of the preferred orientation of the different magnetic carriers, using techniques such as phyllosilicate X-ray pole figure goniometry or AARM. However, also the interpretation of these methods in relation to AMS is not always straightforward [5].

\section{Acknowledgements}

We are grateful to A. Seghedi and G. Oaie for guiding us to outcrops of the Neoproterozoic turbidites of the Moesian platform (Romania). T. Debacker is a Postdoctoral Fellow of the F.W.O.Vlaanderen. M. Sintubin is a Research Associate of the Onderzoeksfonds K.U.Leuven. This work forms part of research project G.0094.01 of the F.W.O.-Vlaanderen. The research in Romania benefits from the International scientific and technological cooperation program from the Science, Innovation and Media Department of the Ministry of the Flemish Community (BIL01/34).

\section{References}

[1] G. Oertel: Tectonophysics Vol. 100 (1983), 413-447.

[2] F. Hrouda: Geophysical Surveys Vol. 5 (1982), 37-82.

[3] G.J. Borradaile and B. Henry: Earth-Science Reviews Vol. 42 (1997), 49-93.

[4] B.A. Housen, C. Richter and B.A. van der Pluijm: Tectonophysics Vol. 220 (1993), 1-12.

[5] T.N. Debacker, P. Robion and M. Sintubin: Geological Society, London, Special Publications Vol. 238 (2004), 77-107.

[6] J. Verniers, A. Herbosch, M. Vanguestaine, F. Geukens, B. Delcambre, J.L. Pingot, I. Belanger, M. Hennebert, T. Debacker, M. Sintubin, and W. De Vos: Geologica Belgica Vol. 4 (2001), 5-38.

[7] C. McCabe, M. Jackson and B.B. Ellwood: Geophysical Research Letters Vol. 12 (1985), 333336.

[8] V. Jelinek and J. Pokorny: Physics and Chemistry of the Earth Vol. 22 (1997), 179-181.

[9] V. Jelinek: Tectonophysics Vol. 79 (1981), 63-67.

[10] G.J. Borradaile: Tectonophysics Vol. 156 (1988), 1-20.

[11]P. Rochette, M. Jackson and C. Aubourg: Reviews of Geophysics Vol. 30 (1992), 209-226.

[12]F. Martín-Hernández and A. Hirt: Tectonophysics Vol. 367 (2003), 13-28.

[13] V. Jelinek: Travaux Géophysiques Vol. 37 (1993), 124-134.

[14]W. Lowrie: Geophysical Research Letters Vol. 17 (1990), 159-162. 
[15]M. Sintubin, H.R. Wenk, and D.S. Phillips: Materials Science and Engineering Vol. A202 (1995), 157-171. 